\title{
Fishing Methods and Occupational Safety Practices of Fishermen in a Coastal Municipality of Central Luzon
}

\author{
Kristine C. Alvina, ${ }^{1}$ Rafael R. Clemente,${ }^{1}$ Mark Cedric M. Fabian, ${ }^{1}$ Lynnell Alexie D. Ong, RMT, ${ }^{1}$ \\ Tricia Mhey R. Rivas ${ }^{1}$ and Paul Adrian V. Pinlac, MD, MPH, MSc ${ }^{2}$ \\ ${ }^{1}$ College of Public Health, University of the Philippines Manila \\ ${ }^{2}$ Department of Epidemiology and Biostatistics, College of Public Health, University of the Philippines Manila
}

\begin{abstract}
Objective. This study aims to explore the fishing methods and occupational safety practices of fisherfolk in a coastal municipality in Central Luzon.

Methods. Key informant interviews were conducted with leaders of fishing organizations and the Municipal Agricultural Officer using a semi-structured interview guide.

Results. Fisherfolk in the selected municipality adopted a variety of fishing practices, equipment, and methods suitable for each individual or group of fisherfolk. Safety practices were either self-learned from observation of elders and family members or arose from a trial-and-error basis, with an emphasis on precautionary measures to avoid injury.
\end{abstract}

Conclusion. Fishing practices highly varies, the most prominent of which is using numerous equipment for catching fish and other marine products by hand. Occupational safety practices are mainly focused on the avoidance of hazards.

Key Words: fishing, occupational health and safety, fishing practices, Philippines

\section{INTRODUCTION}

Poster exhibit in the PH 197/199 Special Studies on April 13, 2019, at the College of Public Health, University of the Philippines Manila, Philippines.

Corresponding author: Kristine Cariño Alvina College of Public Health

University of the Philippines Manila

625 Pedro Gil St., Ermita, Manila 1000, Philippines

Email:kcalvina@up.edu.ph
The Philippines is the world's second-largest archipelagic state, with over 2.2 million $\mathrm{km}^{2}$ of highly biodiverse seas. ${ }^{1}$ As such, the fishing industry in the country is highly developed; the Philippine fishing industry produced P228.9 B of the country's gross domestic product in 2016 and employed an estimated 1.5 million people in $2010 .^{2}$

Fishing at sea is considered the most dangerous occupation in the world. It is estimated by the International Labor Organization that 24,000 fatalities occur worldwide per year. ${ }^{3}$ In 2013, the country's agriculture, forestry, and fisheries sector reported 3,770 cases of occupational injuries; 2,846 with workdays lost, and 924 without workdays lost. It is most likely that these numbers are underestimates due to the lack of established injury reporting in the informal sector. ${ }^{4}$

In the Philippines, the Department of Health issued Administrative Order 2013-0018, which mandates the development of an occupational health program for informal workers in the mining, transport, and agricultural sectors; ${ }^{5}$ however, there is still a lack of occupational health and safety specific programs, projects, policies, and general awareness in the local setting. ${ }^{6}$

According to McDonald and Kucera (2007), those who work in industrialized places often receive training in health and safety from professionals, thus, the idea of "safety" 
is well-known to them. Standardized safety regulations and practices are observed due to foreseeable and repetitive working environments. ${ }^{7}$

Independent non-industrialized fisherfolk do not have access to the safety services normally provided by the industry, therefore they have to decide and develop their safety practices. They are not structured as they may work alone, in pairs, or groups of three, and do not possess a unified safety practice because of their changing working conditions and independent organizations. ${ }^{7}$

Since there is a lack of information and studies regarding the fishing methods and occupational safety practices of fisherfolk in the country, an exploratory case study will better aid in gaining a deeper understanding of the current situation of the fisherfolk. Additionally, this will help in the development of policies and interventions to improve the occupational safety and health of the fisherfolk. The research can also be utilized as a basis for further studies on the occupational health of fisherfolk.

This study aims to explore the fishing methods and occupational safety practices of fisherfolk in a coastal municipality in Central Luzon.

\section{METHODS}

The Municipal Agricultural Officer (MAO) and leaders of local fishing organizations were interviewed individually as key informants regarding the current work and safety practices of fisherfolk in Masantol. The key informant interviews (KII) were conducted by the research team, who received training for data collection through KIIs.

The tools for data collection were two topic guides: one for the MAO and one for the leaders of fishing organizations. The topic guide for the MAO included questions regarding surveillance systems for occupational injury and ongoing and future programs for fisherfolk, while the topic guide for the leaders of the organization included questions seeking to describe fishing methods and occupational safety practices in the municipality. Both were designed in consultation with a faculty member of the Department of Health Promotion and Education in the University of the Philippines (UP) Manila College of Public Health.

Both tools were validated by the Provincial Fishery Officer at the Bureau of Fisheries and Aquatic Resources (BFAR) in Central Luzon Region. Based on the comments provided, the tools were modified before pre-testing. The topic guides were pre-tested in a neighboring coastal municipality, in the presence of the research adviser. The pre-testing site was chosen for its status as a fellow coastal municipality with a large number of fisherfolk.

A list of the Barangay Agriculture Fisheries Council (BAFC) officers for each barangay (village) in Masantol was obtained from the MAO. The barangays were then sorted from highest to lowest number of fisherfolk, and the BAFC officers for all barangays with contact numbers from the list provided by the MAO were contacted to secure their approval to conduct a KII. Those with the highest number of registered fisherfolk that verbally (but informally) consented were interviewed. A total of seven respondents from four barangays who were all leaders or officers in their respective BAFC, which oversees fishing operations at the barangay level, were included in the study. Before the interview, an informed consent form was administered containing the details and objectives of the study. Data saturation was achieved when redundancy was observed in the answers.

The KIIs were recorded and transcribed. As described by Nowell et al. (2017), the thematic method of data analysis was uti-lized wherein answers were tabulated by the question, answer, and explanation for each barangay interviewed. Similar answers for each question were then grouped, and through these answers, themes were reviewed, named, and identified. ${ }^{8}$

Initially identified themes were then further reviewed and defined, and relationships between themes were identified (Figures 2 and 3). The researchers then created an analysis of the thematic map and prevailing themes, utilizing both researcher narration and informant quotations.

The results for the key informant interview with the $\mathrm{MAO}$ were presented in a narrative.

\section{Ethical Considerations}

The study was approved by the UP Manila Review Ethics Board (UPMREB 2018-568-UND). Before the conduct of the KIIs, a written informed consent form was obtained from the key informants. To safeguard the confidentiality of data and privacy of research participants, their identity remained confidential and only the research team had full access to the data.

There are no direct benefits for the study population. However, the results of the study regarding the factors associated with occupational injuries will be beneficial to the $\mathrm{MAO}$ and the fisheries organizations in Pampanga in future planning and development of policies and interventions.

\section{RESULTS}

Thematic analysis was used to analyze the data from the key informant interviews. Themes and patterns were identified among the fishing methods and occupational safety practices of the fishermen in Masantol, Pampanga. For this study, fishing practices will include all things done before, during, and after fishing, including safety practices and fishing methods. Fishing methods are the techniques that fishermen will use to obtain their catch.

\section{Fishing Practices}

\section{Fishing Methods and Equipment}

The fisherfolks in Masantol do not receive any kind of training for fishing. Most of the fishing equipment they use 


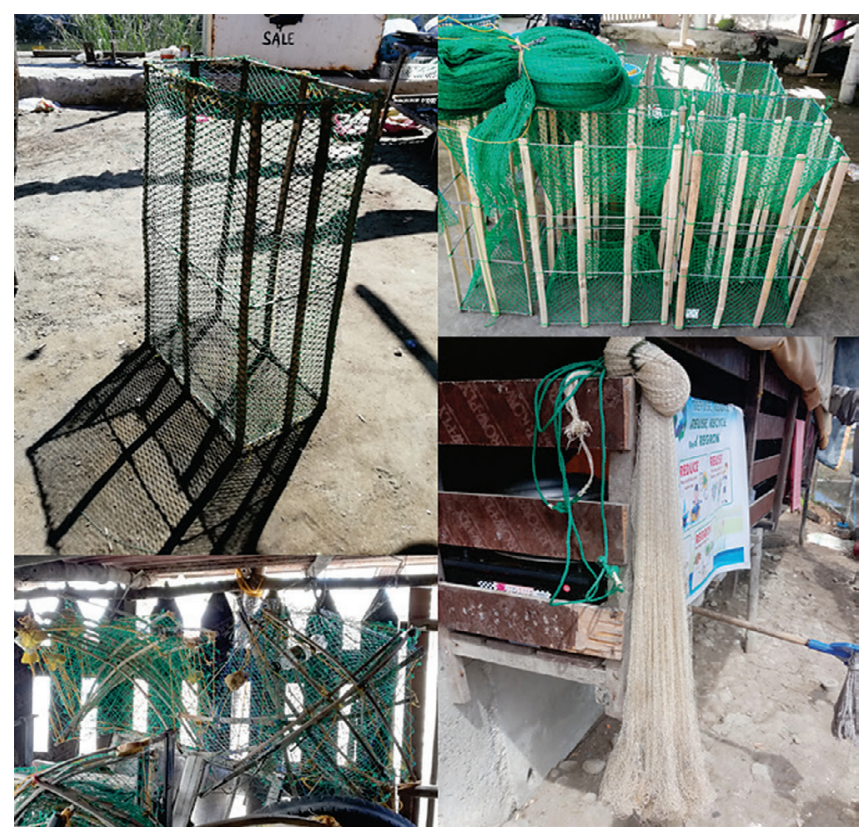

Figure 1. Fishing equipment used by the fisherfolk. Laptop (top left), Bintol (bottom left), Bubo (top right), and Dala (bottom right).

Owner: Mark Fabian (February 28, 2019, Central Luzon).

is inherited from their ancestors or parents. Fish and other marine life are caught using various fishing gears, the most common of which include the "laptop", a rectangular crab trap that was invented by the fisherfolk in Masantol, that is left in the water. The bintol is a similar trap that is pulled up by hand. The kitig or panti is a gillnet that is cast to catch alimasag or small crabs. The kimput or lambat (net) is used for different types of marine life as well as the kitig and sid or screen. The dala is a cast net used for shrimp and fish. Fisherfolks also use their bare hands, sometimes even diving to catch bipon (shrimp) and ulang (large shrimp).

It can also be noted that fisherfolks bring a variety of equipment to ensure that they have a catch.

"Marami kaming dinadalang panguha. Di lang isa. O tingnan mo, magdadala ka ng panti, di makakakuba yung panti, yung sid makakabuli. Di man makakuha yung sid, yung kitig makakabuli. Kasi kung isang bagay lang yung dinadala mo pag wala na uuwi kang wala." (We bring a lot [of gear] to catch fish. Not only one. Look, you will bring panti. If it [panti] couldn't catch fish, the sid will be able to [catch fish]. In case the sid won't be able to catch [fish], the kitig could catch [fish]. If you only bring one thing and if you weren't able to catch fish anymore, you go home with nothing.)

Another important aspect of what equipment will be utilized while working is the income of the fisherman. Some fisherfolk need to save to use different kinds of gear.
"Yung mga trap, binibili kasi kada taon lang po yun eh. Halimbawa, kasi makekwenta mo na yan kung magkano yung kinikita. Kailangan magtabi ka na. O kaya, kapag nabibirapan, syempre. Hintay ka na lang ng swerte, kung sa ibang paraan." (Traps are bought every year. For example, because you can compute how much you will have to set aside from your income, you need to save for it. Or, in harder times, of course. Just wait for luck, if not some other way [you can buy it].)

\section{Fishing Locations}

Access to bodies of water is one of the major contributors to the methods of fishing that fisherfolk in Masantol will adopt. Methods of fishing differ in each barangay, and these may either involve diving (pangangapa, sisid or mano-mano) or using a range of fishing gears such as those mentioned above.

Barangays close to Manila Bay, Pampanga River, and other bodies of water opt for capture fishing, while those barangays which are distant from these bodies of water prefer to cultivate fishes and other marine products in fishponds. One leader shared that the fisherfolk work in areas where they know that they will be able to catch fishes.

"Yung iba pupunta diyan sila sa ilog o sa dagat

kung saan alam nilang meron silang makukuba."

(Others will go to the rivers or the sea where they

know they'll be able to catch something.)

The body of water wherein they fish will also dictate which type of gears they will use, as different bodies of water contain different types of fishes and aquatic life. Local marine products include the following: sugpo (prawn), tilapia, bangus (milkfish), alimasag (blue crabs), alimango (mud crabs), pusit (squid), bipon (shrimp), kanduli (catfish), ayungin (perch fish), biya (goby), and dalag (mudfish).

\section{Time of Departure and Length of Trip}

The time they go out to fish is dependent on certain factors, according to the fisherfolk. Some say they go out in the early afternoon when using nets since fish tend to avoid moonlight. Other fisherfolks go out at midnight.

"Di talaga sila nakakahuli pag maliwanag ang buwan. Parang yung net nakikita ng isda. Pag malakas ang buwan, di mo sila ma-aattract. I mean ano sila...kalat." (Whenever the moon is bright. they are not able to catch fish because it seems that the fishes are able to see the nets. When the moon is bright, you won't be able to attract them [fishes]. They are spread out.)

Fisherfolks also catch different fishes at different times of the day and in varying durations depending on the tides, waves, and the flow of water. During high tide, fisherfolk are unable to catch fishes since high water levels 
and rough waves make it difficult for them to fish. On the other hand, during low tide, fisherfolk prefer to go diving (nangangapa, sisid or mano-mano) since water levels are low.

"Kung anong oras yung low tide, doon sila.

Predeng umaga, pwedeng gabi. Anytime, basta maliit yung tubig. Yun ang binabagayan nila kung kailan maliit yung tubig." (If it's low tide, that's when they fish. It can be in the morning or it can be in the evening. Anytime, as long as the water is low. They base it whenever the water is little.)

Fishing trips of the fisherfolk that go out to sea sometimes take as long as three days to capitalize on the equipment they bring as well as their diesel. Those that dive takes around 4 to 6 hours when they fish, while those that use gillnets take up a whole day because they have to wait for the fish to enter the net.

\section{Boats and Equipment Care}

Fisherfolks mostly use motorized boats, but there are a small number of boats that need to be rowed. Most boats are made of fiberglass, while some are made of wood. The length of the boats ranges from 7 meters to as long as 20 meters.

Boat care includes lining the boat with plywood to prevent water from entering, storing the boats in garages to prevent collisions with other boats, keeping the boats in the water and under the shade, and fixing holes or worn-down portions with chemicals. Both the captain and crew contribute to repairs, the captain especially if the motor is broken.
Income also affects how one can maintain their fishing craft. Fisherfolks rely on themselves and their crew for boat maintenance; a mechanic is only called upon for serious repairs on the engine.

"Sa makina, [yung ipapaayos] kapag medyo light pa, sa amin na kung kaya pa. Pero kapag ano [malala] naman, palit na. Kasi [...] 3,600 bibili, 3,800, kung minsan sisingilin ka ng 1000. Bili ka na lang. Tapos nun may stock yung isa, bili ka ng bago, habang [pinapaayos] yung bago mo, prwede kang, pwede mong gatungin yung isa." (For the engine, when [the repairs] are still light, we do it if we can. But if they're severe, we replace [the engine]. Because it's 3,600 [pesos] when you buy, 3,800 [pesos], sometimes they charge you 1,000 [pesos]. Better to just buy. Then you stock one, buy a new one, while you fuel the old one.)

Equipment is cared for by regularly inspecting for tears or holes, cleaning, and hanging up to dry. Panti, bintol, lambat, and some traps are replaced if broken, or sewn and repaired if still possible. A thematic map of fishing practices is provided in Figure 2.

\section{Occupational Safety Practices}

\section{Precautionary Measures to Avoid Injury}

Injurious equipment such as nets are approached with care. Practices are similar when dealing with a venomous

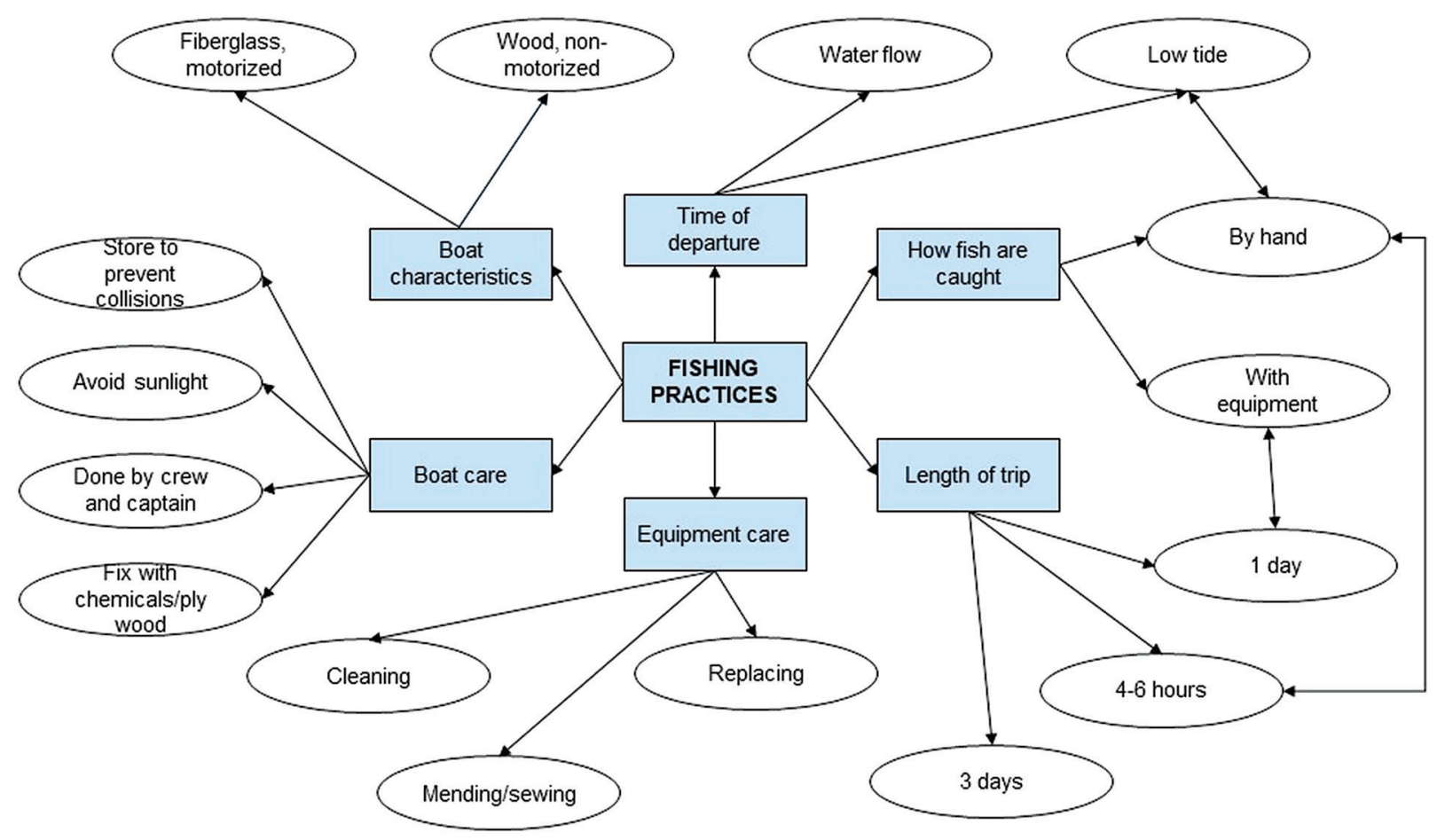

Figure 2. Thematic Map of Fishing Practices of Fisherfolk in a Municipality in Central Luzon, Philippines. 
catch. Awareness of the weather is also inherent to some fisherfolk, while others learn on their own how to gauge if the weather is safe for fishing. Similarly, divers avoid waves to reduce the risk of injury.

\section{Attitude towards Occupational Injuries}

In some cases, safety is abandoned altogether even when sick since the fisherfolks still need to earn money. Fisherfolks in Masantol have generally accepted that injuries and accidents come as part of the job. Injuries are avoided when possible, but when they do occur, they are deemed unremarkable.

"Sir, hindi maiiwasan yun eh. Pero ok lang yun kasi bago ka naman mangisda, alam mo na yun." (You can't avoid it. But it's alright because you already know that [you'll get injured] even before you go out to fish.)

\section{Sources of Safety Knowledge}

Techniques are picked up from elders or done repeatedly until correct. Oftentimes, safety practices are based on personal experience. One leader explained that fishing from a young age makes fisherfolk proficient in their work, reducing their chances of getting injured. Much like fishing practices, safety practices are also self-learned from observation. Ways to keep safe while diving for catch also arise from a trial-and-error basis.

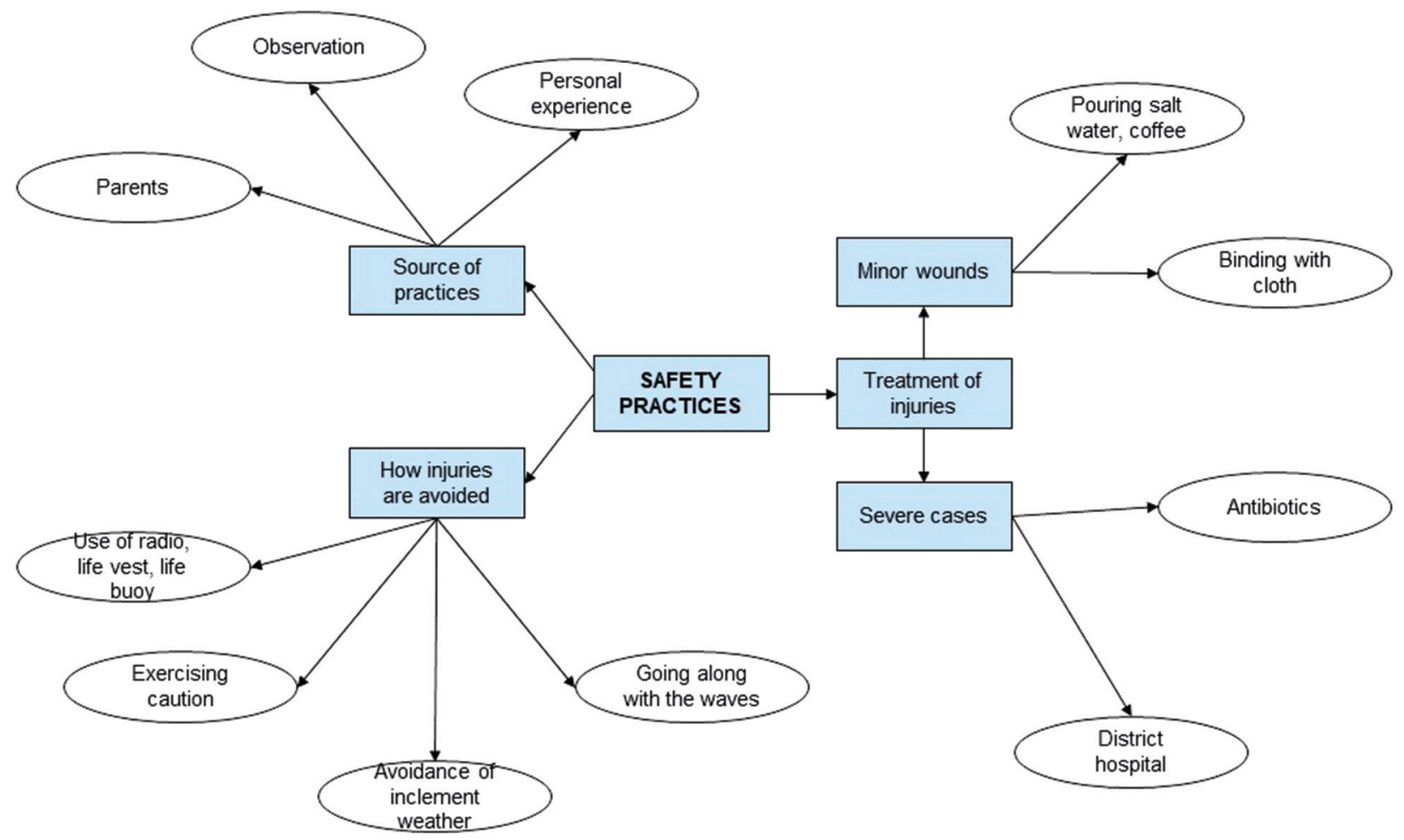

\section{Treatment and Treatment Seeking Behaviors}

Treatment for minor wounds is improvised from what is available in the area. Those that are proven effective are used in subsequent occurrences of injury and are mostly self-taught.

Due to the distance of the rural health unit and the district hospital, fisherfolk usually wait for the injury to heal itself. "Tiis-tiis lang." (Just bear with it.) Hospital treatment is only sought when injuries are severe. A thematic map of occupational safety practices is provided in Figure 3.

\section{Factors Affecting Fishing Practices}

\section{The Impact of Socio-Economic Status}

One of the biggest influencers of fishing practices in Masantol is the socioeconomic status of the fisherfolk. These workers are born into the lower class and often did not finish their studies; knowledge regarding fishing practices is passed on from generation to generation, and the researchers did not encounter any fisherman who received formal training regarding their craft.

"Kaya maraming dito sa bayan namin, maraming hindi edukada, edukado hindi, marami. Maraming bindi, kumbaga sa may propesyonal. Ganun po yung kalakaran po dito." (A lot of us in our town aren't educated. There's not a lot of professionals. That's the way things are here.)

Figure 3. Thematic Map of Safety Practices of Fisherfolk in a Municipality in Central Luzon, Philippines. 
Since these fisherfolk have not finished their schooling, they cannot take up "professional" careers requiring college degrees, forcing them to fish for a living. One leader said fishing is a tradition and not doing so would be a wasted opportunity since it is profitable.

Consequently, what they earn is only enough for their day-to-day lives, and some of their earnings also have to be set aside for repairs and other needs for their livelihood. As a result, fisherfolk cannot provide higher education for their children, repeating the cycle.

\section{Practices Inherited from Ancestors}

Fishing is one of the main sources of livelihood in Masantol, Pampanga as it is passed on from generation to generation. Specific methods used for fishing are taught by their ancestors and are passed on.

It was noted by the fisherfolk that their way of life as a whole is a result of where they originated. In childhood, since they saw older people using lambat (gill net) they learned and imitated what they saw and used the same fishing gear later in life.

"Yun na po talaga yung ano namin sa ancestor pag dito ka nakatira, nakikita mo silang naglalambat, matututo ka. Parang ano lang yan... salin salin, nagaya ka." (That's what our ancestors did, most especially when you live here, you observe them using nets so you learn how. It's like... you replicate, you do the same thing."

Moreover, from these traditions, one fisherman claimed that they invented new fishing gears, some of which are upgrades of what they have inherited from the previous generations.

\section{Practices as Affected by Personal Experiences}

Most of the leaders claim that techniques in fishing cannot be taught; fisherfolk learn their techniques by observation of "seniors" in their line of work. During his first trip into the waters, an aspiring fisherman is tested if they can carry on the profession.

"Kabit yung pagsama sa dagat, pag-sumama ka sa dagat, syempre sa una, manonood-nood ka. Tapos pag-alam mo na ang gagawin mo, alam mo saan itataya yung katawan mo. Alam mo kung saan ka epektibong....may mga ano kasi yan eh, may kanyakanyang trabaho doon sa bangka. [...] Doon yan natututo. Pag bindi ka natuto, sa susunod, bindi ka na makakasakay. Hindi ka na isasama." (In joining a trip to the sea, at first, you just observe. Then when you know what you need to do, you know what job you can do best. You know where you can work more effectively... There are different jobs on the boat. That's where you learn. If you don't learn then, you can't board [the boat] next time. You won't be part of the crew.)

As stated earlier, since they work together when fishing, fisherfolk make and use the same fishing gear. There are times when they help one another upon making the gears which takes time before they can do it perfectly. Fishing practices are also dependent on the current state of the river (high or low tide). The way they estimate the river currents depend on

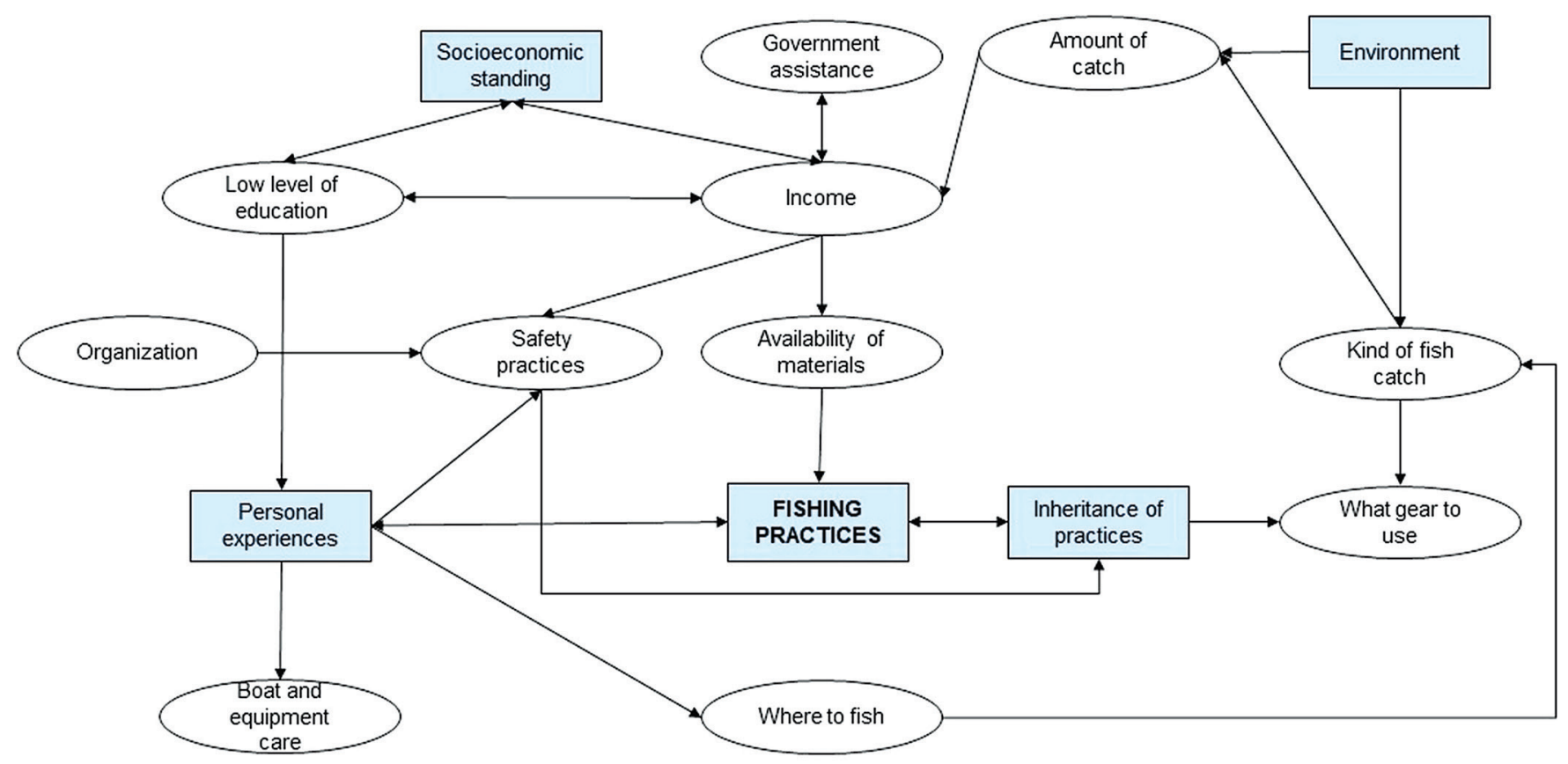

Figure 4. Relationships Between Fishing Practices and Other External Factors. 
their personal experiences. The relationships between fishing practices and other external factors are outlined in Figure 4.

\section{Individual Interview with the Municipal Agri- cultural Officer}

The occupational injuries of fisherfolk in the municipality, an important indicator for their safety practices and occupational health, were not being monitored by a surveillance system. Instead, a surveillance system was in place for the monitoring of areas in times of calamities. The focus of the MAO during times of calamities are not directed at the people, but rather, at the gears and the fishery production.

The only program or intervention that the Municipal Agricultural Office has for the occupational safety of the fisherfolk is the distribution of life vests done once or twice a year. This program has been ongoing for more than three years. The life vests come from the BFAR, and the MAO distributes them to the fisherfolk. However, only a limited number of 10 to 20 life vests are given per year; a priority system is in place which is used to select a limited number of underprivileged fisherfolk to receive the life vests.

Presently, the MAO has no plans of implementing a program for the occupational safety of the fisherfolk since the focus of their department is on the economic productivity of fisheries in Masantol.

The results show that fishing practices in Masantol, Pampanga are influenced, directly or indirectly, by three main factors: environment, the inheritance of practices, and socioeconomic status. The environment dictates where fisherfolk will fish, how much they will catch, what kind of catch they will obtain, and what gear to use to catch them. Inheritance of practices is related to gear use and safety practices. To some extent, personal experiences affect safety practices, fishing location, and boat and equipment care. Finally, the socioeconomic status of fisherfolk will affect their level of education and income. Consequently, income affects the extent of government assistance and the availability of materials to be used for fishing, while the low level of education will affect personal experiences regarding equipment care.

\section{DISCUSSION}

\section{Fishing practices}

Fishing practices in Masantol, Pampanga are inherited from their ancestors, which is comparable to a similar study conducted in the Northeast frontier of India wherein old traditional methods of fishing are prevalent. Most of their practices are primitive and outdated as no new and reliable technology is available. Likewise, their methods range from catching with hands and use of indigenous nets. ${ }^{9}$ According to Shrinath and Kajeev, the fisherfolk in India are also mostly unprepared for the injured or sickly crew on board. ${ }^{10}$

Similarly, various factors such as the physical geography of bodies of water, nature of fish supply, and level of water affect how they select the fishing methods and gear that will be used. Some fishing gears were used by both populations like: hook and lines, cast net, gill net, dragging gears, and fish traps. It can be noted that some specific fishing methods are very effective to catch a particular fish. ${ }^{9}$

In a study conducted on the fisherfolk of Honda Bay, Palawan, it was also noted that the corresponding efficiency of the different fishing gears used determines the fisherman's capability to harvest more or less fish. Another point of likeness between the fishing population in Honda Bay and Masantol is the role that the socioeconomic standing of fisherfolk plays in the availability of resources that can be used for fishing. Larger gear that can catch more fish requires a larger capital, and those with a large capital can also purchase more boats. ${ }^{11}$

Moreover, personal experiences also play an important role in the daily lives of the fisherfolk. Their knowledge about how and where to fish were obtained not just from their experiences but through the observations of others. Oftentimes, they gather these observations by joining the older fisherfolk when they fish in the river-all of which are in line with a study conducted in the Philippines by Siar, (2003) wherein the younger children also acquire their knowledge by fishing with their fathers or uncles then observing their line of work. In like manner, the access to resources depends on the individual level of knowledge of the fisherfolk with regards to fishing. ${ }^{11}$

One may also note that fisherfolk in the selected municipality observe how the various fishing gears or methods are used by their seniors and later on apply them to their livelihood later on in life. Personal experience is gained after knowing how to use the fishing gear and their first trip to the sea. As a result of this, the experiences help them learn and determine what work and fishing methods suit them the best. Similarly, according to Siar (2003), the methods used in the region of her study resulted from the personal experiences gained by the fisherfolk over a period of time. ${ }^{11}$

\section{Safety practices}

The geography of the area is a large contributor to fishing practices and, by extension, safety practices. Fisherfolk who are injured do not seek treatment from capable agencies, but would rather wait for these injuries to heal because they are geographically isolated from hospitals, rural health units, and the like. A rural community in Wakiso district, Uganda, similarly stated that a barrier to seeking treatment is the long distance from their homes to the nearest health facility. ${ }^{12}$

The research team also conducted a visit to the Municipal Health Officer, but no information about existing occupational safety programs for fisherfolk and other agricultural workers was obtained, including the absence of a surveillance system for occupational injuries. These findings contribute to the state of underreporting of occupational injuries in both the fisheries sector and the informal sector. 
This lack of surveillance may be one of the reasons why proper interventions and programs cannot be formulated: health surveillance is necessary to determine undesirable health effects resulting from workplace exposure and is used as a benchmark to create effective prevention measures. ${ }^{13}$

Most knowledge regarding fishing practices and prevention and treatment of injuries come from either what they have been taught by their family members or observed from elders. It can be inferred that these members of the community are instrumental in shaping and influencing their safety practices. If these people are taught the importance of occupational safety and health and proper prevention and treatment of injuries while fishing, it may cause a ripple effect on those who observe them and to those they teach. Indeed, in a study conducted in Tokyo, Japan, participants who were part of a health literacy program spearheaded by community leaders had better health literacy (and health behaviors, in general) compared to the general population. ${ }^{14}$

Taking all these into consideration-geographical isolation, lack of education, and adoption of practices based on community elders-can be the foundation of formulating an occupational health and safety program tailored to this particular population.

\section{CONCLUSION AND RECOMMENDATIONS}

The KII revealed that fishing practices in Masantol, Pampanga are highly varied, the prominent methods of which are using a large number of equipment or catching fish and other marine products by hand. Occupational safety practices are mainly focused on the avoidance of hazards. Fishing practices were found to be influenced by geography, inheritance, and socio-economic status.

Fisherfolk in the municipality view occupational injuries as unavoidable and use alternative methods of healing such as pouring coffee and vinegar or soaking wounds in saltwater. It is recommended that these fisherfolk be given short courses or lectures on occupational health and safety, the possible injuries that they may incur from the different types of marine life that they catch, and the possible complications of those injuries if left untreated or mistreated.

The interviews also revealed that fisherfolk are not able to voice their concerns regarding their fishing practices and safety at work. The involved government agencies, such as the Department of Health, Department of Agriculture, and the Department of Labor and Employment, are then recommended to establish an avenue for regular communication of grievances and other concerns with the leaders or representatives of each barangay in the municipality, especially barangays that are most distant from their offices.

Additionally, there is currently no surveillance system in place for the fishermen. In light of this, a surveillance system that aims to monitor the types and causes of occu- pational injuries of fishermen is also recommended to be established. This will be headed by the Municipal Health Office but should be acted on at the barangay level where a Barangay Health Worker will actively collect the information from active fishermen. All of the data collected should be transmitted to the respective agencies.

Possible direction of future studies may seek to discover the correlation between fishing methods, fishing equipment, and other factors mentioned in this study to the occurrence of occupational injuries.

\section{Limitations of the study}

Information gathered through the interviews were self-reported and not observed, and therefore might not be wholly accurate and may contain intentional and unintentional reporting bias. Triangulation of data to verify the responses from the interviewees were not done given the time constraints in which the study could be implemented by the research team. While it is notable that it is crucial to confirm self-report of behavior ideally through observation, the visits were conducted during the interviewees' free time, preventing the researchers from doing data collection outside methods of query and review of records. Nonetheless, findings from this exploratory study will be undeniably useful as a springboard for another researcher who would like to pursue a more in-depth qualitative study on the safety practices of fisherfolk.

Other agencies such as the rural health unit were not interviewed, therefore any information these agencies could have provided regarding occupational safety of fisherfolk were excluded. The safety practices in this study may only apply to the described population. Also, this is the first study describing occupational safety practices of fisherfolk in the Philippines. The authors recognize that the interviews conducted may not have been exhaustive of all safety practices utilized by the study population.

\section{Acknowledgments}

The proponents of this study would like to acknowledge the contributions of Engr. Arlene Bonifacio, Ms. Carlamay Guevarra, Ms. Susan Sunga, Mr. Rafael Navarro, Mr. Danilo Guinto, Ms. Arian Ignacio, Ms. Lanie Lamyong, and Dr. Nona Rachel C. Mira.

\section{Statement of Authorship}

Kristine C. Alvina, Rafael R. Clemente, Mark Cedric M. Fabian, Lynnell Alexie D. Ong, and Tricia Mhey R. Rivas - concept and design; data acquisition, analysis, and interpretation; drafting, revising, and final approval of the manuscript; agree to be accountable for all aspects of the work.

Dr. Paul Adrian V. Pinlac - concept and design; data interpretation; revising and final approval of the manuscript; agree to be accountable for all aspects of the work.

All authors approved the final version submitted. 


\section{Author Disclosure}

All authors declared no conflicts of interest.

\section{Funding Source}

None.

\section{REFERENCES}

1. FAO Fisheries \& Aquaculture- Country Profile. [Internet]. [cited 2020 February 14.] Available from: http://www.fao.org/fishery/facp/ PHL/en\#CountrySector-Overview.

2. PSA. Fisheries Statistics of the Philippines, 2014-2016. Quezon City, Philippines.

3. FAO 2000. The state of world fisheries and aquaculture. [Internet]. [cited 2020 February 14.] Available from: http://www.fao.org/3/ $\mathrm{x} 8002 \mathrm{e} / \mathrm{x} 8002 \mathrm{e} 00 . \mathrm{htm}$

4. PSA. Safety and Health in the Workplace Cases of Occupational Injuries (First of a Series). [Internet].; 2017 [cited 2020 February 14.] Available from: https://psa.gov.ph/content/safety-and-healthworkplace-cases-occupational-injuries-first-series-2.

5. Department of Health (DOH). Administrative order 2013-0018. Manila, Philippines.

6. Cadiz A, Camacho V, Quizon R. Occupational health and safety of the informal mining, transport and agriculture sectors in the Philippines. Southeast Asian J. Trop. Med. Public. Health. 2016 Jul 1;47(4):833-43.
7. McDonald M, Kucera K. Understanding non-industrialized workers' approaches to safety: How do commercial fisherfolk "stay safe"? Journal of Safety Research. 2007; 38(3): p. 289-97.

8. Nowell LS, Norris JM, White DE, Moules NJ. Thematic analysis: Striving to meet the trustworthiness criteria. International Journal of Qualitative Methods. 2017; 16:1-13. https://doi.org/10.1177\% 2F1609406917733847

9. Gurumayum SD, Choudhury M. Fishing methods in the rivers of Northeast India.

10. Srinath K, Rajeev P. The use of sea safety measures by fisherfolk. Marine Fisheries Information Service, Technical and Extension Series. 1995;139:8-9.

11. Siar SV. Knowledge, gender, and resources in small-scale fishing: the case of Honda Bay, Palawan, Philippines. Environmental Management. 2003 May 1;31(5):0569-80.

12. Musoke D, Boynton P, Butler C, Musoke MB. Health seeking behaviour and challenges in utilising health facilities in Wakiso district, Uganda. African health sciences. 2014;14(4):1046-55.

13. Koh D, Aw TC. Surveillance in occupational health. Occupational and environmental medicine. 2003 Sep 1;60(9):705-10.

14. Yajima S, Takano T, Nakamura K, Watanabe M. Effectiveness of a community leaders' programme to promote healthy lifestyles in Tokyo, Japan. Health Promotion International. 2001 Sep 1;16(3): 235-43.

\section{The Acta Medica Philippina is now accepting limited advertising for its front and back cover (colored), as well as for available spaces in some of its pages, as appropriate. For inquiries and submission of proposals, please email us at actamedicaphilippina.upm@up.edu.ph}

